\title{
Gene markers in dendritic cells unravel pieces of the skin sensitization puzzle
}

\author{
Nathalie Lambrechts ${ }^{\mathrm{a}, \mathrm{b}, *}$, Hanne Vanheel $^{\mathrm{a}}$, Jef Hooyberghs ${ }^{\mathrm{a}, \mathrm{c}}$, Patrick De Boever ${ }^{\mathrm{a}}$, Hilda Witters ${ }^{\mathrm{a}}$, \\ Rosette Van Den Heuvel ${ }^{a}$, Viggo Van Tendeloo ${ }^{d}$, Inge Nelissen ${ }^{a}$, Greet Schoeters ${ }^{\mathrm{a}, \mathrm{b}}$ \\ a Flemish Institute for Technological Research (VITO N.V.), Environmental Risk and Health Unit, Toxicology, Belgium \\ ${ }^{\mathrm{b}}$ University of Antwerp, Department of Biomedical Research, Belgium \\ ${ }^{\mathrm{c}}$ Hasselt University, Department of Mathematics, Physics and Informatics, Belgium \\ ${ }^{\mathrm{d}}$ University of Antwerp, Vaccine E' Infectious Disease Institute (Vaxinfectio), Laboratory of Experimental Hematology, Belgium
}

\section{A R T I C L E I N F O}

\section{Article history:}

Received 12 February 2010

Received in revised form 19 March 2010

Accepted 5 April 2010

Available online 10 April 2010

\section{Keywords:}

Skin sensitization

VITOSENS $^{\circledR}$

Novel biomarkers

\begin{abstract}
A B S T R A C T
The underlying events of how dendritic cells (DC) are capable of evoking an antigen-specific skin sensitization response are not yet understood. Recently, we revealed a set of genes in human cord blood CD34 ${ }^{+}$DC (CD34-DC) that show a discriminating behaviour after skin sensitizing exposure. Based on their differential expression, an in vitro assay was developed to identify chemicals as sensitizing or not.

This study was designed to investigate the genes' involvement in the DC response to skin sensitizers and as such gain insights in the sensitization cascade.

Functional connection of the marker genes was inquired by constructing a molecular network using Ingenuity software. By real-time RT-qPCR, we established the effective expression of 3 additional gene transcripts in the generated network in CD34-DC, of which CREB1 and TNF- $\alpha$ were significantly altered in expression by sensitizing versus non-sensitizing exposure.

Next, it was tested whether the discriminating response of CCR2 and COX2 marker genes was translated at the protein level in CD34-DC exposed to 3 sensitizers versus 3 non-sensitizers. Significantly differential protein expression of CCR2 and COX2 was confirmed using flow cytometry.

Our results indicate that the marker genes may be functionally relevant in DC mediated skin sensitization.
\end{abstract}

(c) 2010 Elsevier Ireland Ltd. All rights reserved.

\section{Introduction}

Skin sensitization is characterized by a series of critical events following skin contact with a substance of low-molecular weight. Dendritic cells (DC) act as orchestrators in this by recognizing, internalizing, processing and finally presenting chemical haptens as true antigens on their surface (Banchereau and Steinman, 1998). This elicits an immune response by activation of naïve T cells (Cella et al., 1997).

Dendritic-like cells derived from human primary sources are valuable in vitro cell models to mimic in vivo skin DC. The main primary-derived human DC models are generated either from human CD14 $4^{+}$peripheral blood monocytes (CD14-DC) (Lenz et al., 1993; Romani et al., 1994; Sallusto and Lanzavecchia, 1994) or from cord blood or bone marrow-derived $\mathrm{CD} 34^{+}$hematopoietic precursors (CD34-DC) (Caux et al., 1996; Inaba et al., 1992). These in vitro

\footnotetext{
* Corresponding author at: Flemish Institute for Technological Research (VITO N.V.), Environmental Risk and Health Unit, Toxicology, Boeretang 200, $2400 \mathrm{Mol}$, Belgium. Tel.: +32 143351 07; fax: +3214582657.

E-mail address: nathalie.lambrechts@vito.be (N. Lambrechts).
}

models respond to sensitizing chemicals and may be useful for hazard identification of skin sensitizers (Ryan et al., 2007). The key to successful identification of such chemicals is a test system based upon discriminating markers that are relevant in the biology of skin sensitization. Although our understanding of these immunological mechanisms remains far from complete, multiple biomarkers in primary DC have been proposed to represent crucial events in DC mediated skin sensitization. After antigen-capturing and processing, DC present the antigen on their surface by engaging in a maturation program which includes morphological, phenotypic and functional changes (Saint-Mezard et al., 2004). Increased expression of co-stimulatory surface molecules has been examined extensively and CD86 appears to be the most promising marker in primary DC (dos Santos et al., 2009). Also changes in cytokine secretion such as IL-1 $\beta$ occur upon DC maturation. These signaling molecules have been explored as well as possible biomarkers for chemical-induced sensitization (dos Santos et al., 2009). However, response patterns of both surface and cytokine biomarkers have indicated that their expression profiles have a limited dynamic range and may be chemical-dependent, which is not sufficient for the identification of all sensitizers (Casati et al., 2005). Transcript profiling is a more recent approach that allows to detect genomic 
fingerprints that are induced in DC by chemical sensitizers, leading to novel and unique potential biomarkers of DC interaction with these compounds (Cluzel-Tailhardat et al., 2007; Ryan et al., 2004; Schoeters et al., 2007; Szameit et al., 2008, 2009). Using microarray experiments on exposed CD34-DC, we reported the identification of a novel gene set that has a highly significant capability to distinguish chemical skin sensitizers from non-sensitizers (Schoeters et al., 2007). Discriminant analysis of the expression changes of a selected set of these markers after CD34-DC exposure to an extended set of 21 chemicals, resulted in the VITOSENS ${ }^{\circledR}$ classification assay with an accuracy of $89 \%$, specificity of $97 \%$, and sensitivity of $82 \%$ based on 73 samples (Hooyberghs et al., 2008). ${ }^{1}$

Understanding the mechanisms through which chemical allergens induce contact sensitization in humans is indispensable for assessing this toxicological effect without the need for animal testing. Consequently, in this study the mechanism by which the VITOSENS ${ }^{\circledR}$ assay recognizes skin sensitizing chemicals was investigated. First, a literature-based network connecting the 13 novel biomarkers for sensitizing exposure of CD34-DC was constructed. Expression of potentially relevant members of this network was evaluated by real-time RT-qPCR. In addition, the expression of a confined selection of the 13 biomarkers was investigated at protein level.

\section{Materials and methods}

\subsection{Pathway analysis}

\subsubsection{Network generation}

Thirteen genes (ABCA6, AQP3, CCR2, CCR7, COX2, CREM, CXCR4, ENC, MAD, NINJ, $P B E F 1, P S C D B P$ and SLC2A3) (Hooyberghs et al., 2008) were imported into IPA 7.5 (Ingenuity Systems, Inc., Mountain View, USA) to generate a putative cellular network based on the large manually curated knowledge database of pathway interactions extracted from the literature. The HUGO Gene Symbols of the marker genes were entered in the IPA database as input for analysis by the 'my pathways' option. Relationships between the 13 biomarkers were created by the 'connect' tool based on information contained in Ingenuity's Knowledge Base. Subsequently, molecules were added to this pathway in order to connect all 13 molecules with maximum 1 intermediate molecule by the option 'Path Explorer - Shortest Path/Shortest Path +1 '. These network eligible molecules were algorithmically generated based on their connectivity. A detailed description on the statistics behind the interactions can be found at www.ingenuity.com. Three criteria were set before adding relationships and molecules. First, both direct and indirect relationships were allowed. Second, only molecules that were previously described in human immune related primary cells, cell lines, and epidermal tissue were considered for pathway analysis. And third, except for biologic drugs and any sort of chemical, all types of interaction molecules were accepted in the network.

Using the 'overlay canonical pathway' tool, we identified the 'well recognized' or 'canonical' pathways of which a molecule was present in the generated network. From the gene ontology annotations in the IPA 'molecule summary', the function of the molecules could be derived.

\subsubsection{Real-time $R T$ - $q P C R$}

In the software-generated network, cAMP responsive element binding protein (CREB)1, nuclear factor of kappa light polypeptide gene enhancer in B cells (p105) $(N F-\kappa B) 1$, and tumour necrosis factor $\alpha(T N F-\alpha)$ were selected to confirm their active involvement as pathway members because of their interactions with VITOSENS ${ }^{\circledR}$ biomarkers and relevant biological roles. cDNA samples from the exposure experiments described by Hooyberghs et al. (2008) were used. The samples were confined to those exposed compounds that were classified correctly by the VITOSENS ${ }^{\circledR}$ assay. The test set of skin sensitizing chemicals included ammonium hexachloroplatinate IV ( $\mathrm{HCPt}$ ), cinnamaldehyde (CA), dinitrochlorobenzene (DNCB), 2,4-dinitrobenzenesulfonic acid (DNBS), dinitrofluorobenzene (DNFB), eugenol, nickel sulfate $\left(\mathrm{NiSO}_{4}\right), 2$-mercaptobenzothiazole (2-MBT), and tetramethylthiuram disulfide (TMTD). The 5 non-sensitizers were represented by methyl salicylate (MeSA), para-aminobenzoic acid (pABA), phenol, sodium dodecyl sulfate (SDS), and zinc sulfate $\left(\mathrm{ZnSO}_{4}\right)$. In our previous study, all chemicals were applied to the cells at a concentration that induced $20 \%$ cell growth inhibition, except for MeSA and $p A B A$ which were used at the highest soluble concentration (Hooyberghs et al., 2008). DC cultures from 3 different donors were used for each test substance, except after treatment with DNCB where DC from only 2 donors were analyzed. This led to

\footnotetext{
1 This assay is currently patent pending (WO/2008/037806).
}

a total number of 41 donor samples in this analysis that were each exposed for 6 , 11 , and $24 \mathrm{~h}$.

Real-time RT-qPCR was performed on 20 ng cDNA with the LightCycler ${ }^{\circledR} 480$ SYBR Green I Master mix $(2 \times)$ (Roche Applied Science, Mannheim, Germany) on a LightCycler ${ }^{\circledR} 480$ Instrument (Roche Applied Science) according to instructions of the manufacturer. For each sample 5 reference genes were measured (GAPDH HPRT, SDHA, RPLI3A, YWHAZ). Primers were designed using Primer Express ${ }^{\circledR}$ Software v3.0 from Applied Biosystems (Halle, Belgium) and thoroughly tested (primer sequences are available upon request). Gene expression changes were analyzed using the Biogazelle qBasePlus software (www.qbaseplus.com Biogazelle, Ghent Belgium) (Hellemans et al., 2007). Gene expression changes were determined as fold-changes of exposed samples over corresponding solvent control samples. They were transformed by a 2-base logarithm and addressed further as logarithmic foldchanges (LFC). A LFC of 1 and -1 is representative for a fold-change of 2 and 0.5 , respectively.

Comparisons of the induced LFC for CREB1,NF- $\kappa B 1$, and TNF- $\alpha$ between skin sensitizer and non-sensitizer exposed donors were performed using a 1-tailed Student's $t$-test for samples with unequal variances. A $p<0.05$ was considered statistically significant for all analyses.

Visual presentation in a heatmap of the mean LFC in CD34-DC was done by TM4 Software Suite: TIGR MultiExperiment Viewer v4.0 (http://www.tm4. org/mev.html).

\subsection{Protein detection}

\subsubsection{Generation of $C D 34^{+}$progenitor-derived $D C$}

$\mathrm{CD} 34^{+}$-cell isolation and culture procedures have been described before (Schoeters et al., 2007). Briefly, human cord blood samples were collected from the umbilical blood vessels of placentas of normal, full-term infants. Informed consent was given by the mothers and the study was approved by the ethical commission of the Heilig Hart hospital in Mol, Belgium and the St. Dimpna Hospital in Geel, Belgium. Mononuclear cells were separated from the cord blood by density gradient centrifugation and subsequently $\mathrm{CD} 34^{+}$progenitor cells were extracted by positive immunomagnetic selection. These cells were cultured in Iscove's modified Dulbecco's medium (IMDM) in the presence of TNF- $\alpha$ (Roche Applied Science, Upper Bavaria, Germany), GM-CSF (Gentaur, Brussels, Belgium), SCF (Biosource, Nivelles, Belgium) and IL-4 (Biosource) to induce proliferation and differentiation towards immature CD34-DC according to the method described by Lardon et al. (1997).

\subsubsection{Chemical exposure of $C D 34-D C$}

At the end of the 12-day culture period, immature DC from each donor were exposed in 6-well plates to a confined selection of chemicals: 3 sensitizers (DNFB $(11 \mu \mathrm{M})$, dihydroquinone (DHQ) $(59 \mu \mathrm{M}), 2-\mathrm{MBT}(420 \mu \mathrm{M}))$, and 3 non-sensitizers (dimethylsulfoxide (DMSO) $(64 \mu \mathrm{M}), \mathrm{MeSA}(822 \mu \mathrm{M})$, and $\mathrm{ZnSO}_{4}(440 \mu \mathrm{M})$ (all from Sigma-Aldrich except for DMSO that was obtained from LabScan Ltd, Dublin, Ireland) for 24 and $48 \mathrm{~h}$. The concentrations used in exposure experiments yielded around $80 \%$ cell viability at $24 \mathrm{~h}$, as previously determined on at least 3 biologica replicates (Hooyberghs et al., 2008; Lambrechts et al., 2010). Since no cytotoxicity was found for MeSA, this compound was used at the highest soluble concentration. For each chemical and its corresponding solvent, 3 independent exposure experiments were performed. The chemicals were dissolved in culture medium (DHQ DMSO and $\mathrm{ZnSO}_{4}$ ) or prepared in a $100 \%$ DMSO stock solution and then further diluted in medium up to a final $0.05 \%$ (v/v) DMSO concentration (DNFB, 2-MBT and MeSA). Viability of the cells after 24 and $48 \mathrm{~h}$ of exposure was assessed using propidium iodide staining and flow cytometry since phenotypical analyses needed to be performed on cells with a viability of at least $70 \%$.

\subsubsection{Flow cytometry}

After chemical treatment, the protein expression of intracellular CCR2 and COX2 together with the well-known DC surface markers HLA-DR, CD86, and CD83 was evaluated using flow cytometric experiments. COX2 was chosen for its central role in the network whereas CCR2 was selected for its high discriminating power between skin sensitizers and non-sensitizers (Hooyberghs et al., 2008). The chemokine receptor CCR2 exists as 2 isoforms (CCR2a and CCR2b) as a result of alternate splicing from the same gene (Charo et al., 1994). The differentially expressed transcript that we previously identified by microarray analysis is the CCR2a variant which is known to be located predominantly in the cytoplasm (Wong et al., 1997). The antibody we used, anti-CCR2-PE (clone 48607.211) (R\&D Systems, Minneapolis, USA), cannot discriminate between both isoforms and therefore was used to detect both CCR2a and CCR2b. Total CCR2 expression was measured using intracellular staining on permeabilized cells because this results in the labeling of both surface (CCR2b) and intracellular protein (CCR2a). CCR2b expression was quantified by surface staining of non-permeabilized cells. We than considered expression of CCR2a as the difference of total CCR2 and CCR2b. For simplicity in the text, CCR2a is further referred to as CCR2.

To determine expression of surface proteins after 24 and $48 \mathrm{~h}$ of exposure, CD34DC were harvested and suspended at $1 \times 10^{5}$ cells in $50 \mu \mathrm{lPBS}^{-}$with $1 \%(\mathrm{w} / \mathrm{v})$ bovine serum albumin (BSA; Sigma-Aldrich). Cells were then incubated for $30 \mathrm{~min}$ at $4{ }^{\circ} \mathrm{C}$ with $2 \mu \mathrm{l}$ of antibody, except anti-CCR2-PE of which $10 \mu \mathrm{l}$ was added. For intracellular staining of CCR2 and COX2, cells were first permeabilized in FACS Lysing 


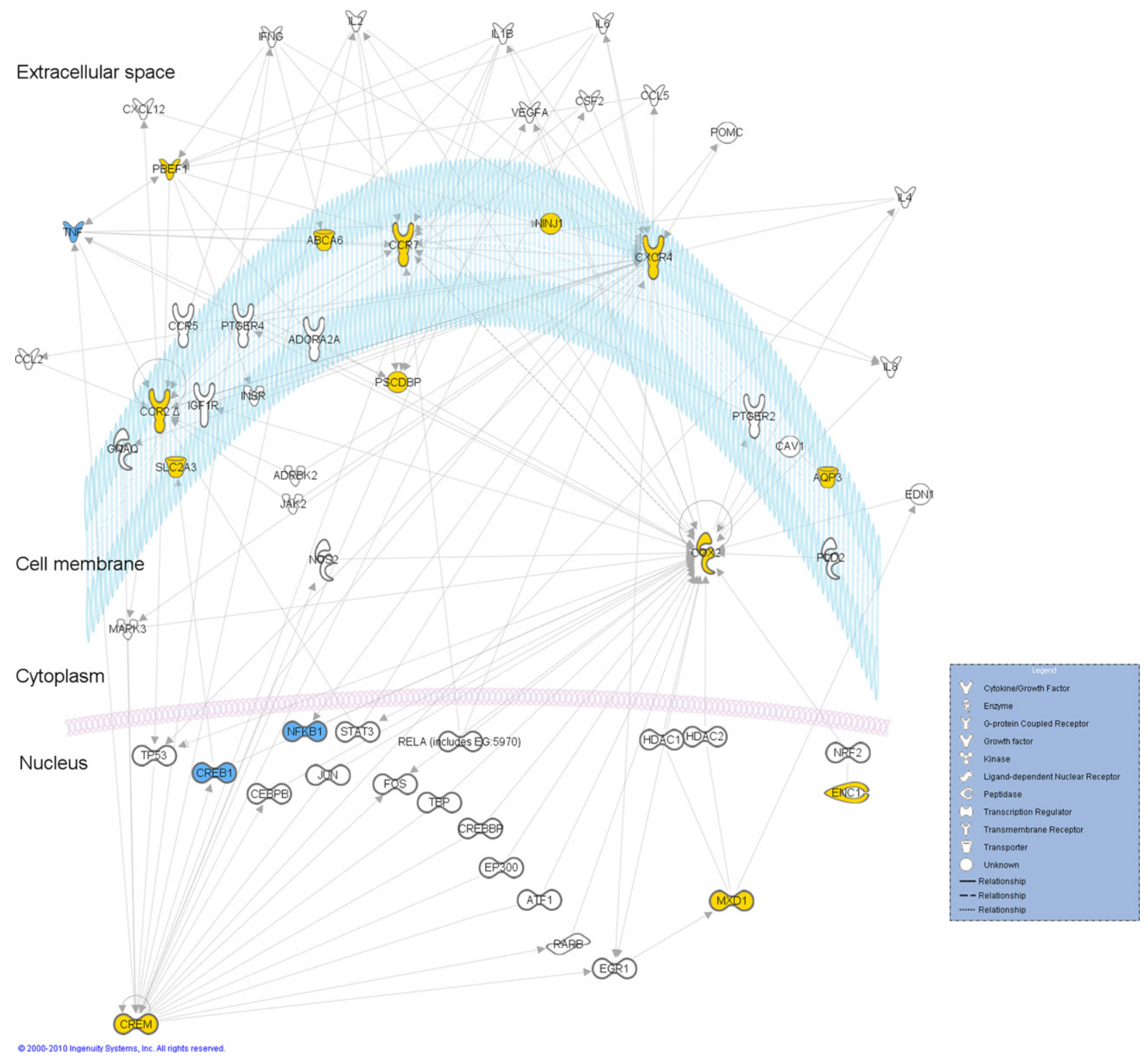

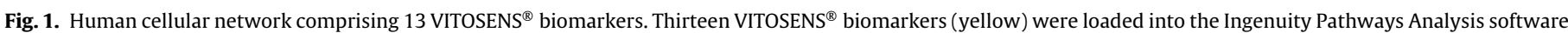

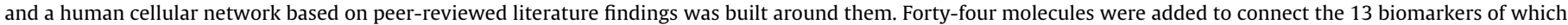

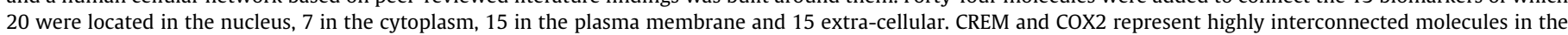

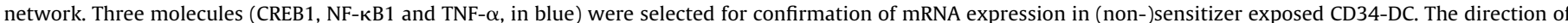

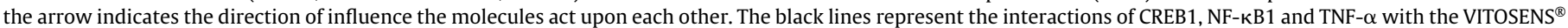
biomarkers.

Solution (BD Biosciences; San Jose, USA) with 0.2\% (w/v) saponin (Sigma-Aldrich) during $10 \mathrm{~min}$ at room temperature. After washing the cells in $1 \mathrm{ml} \mathrm{PBS}^{-}$with $1 \%$ $(\mathrm{w} / \mathrm{v})$ BSA and $0.1 \%(\mathrm{w} / \mathrm{v})$ saponin, they were suspended in $1 \times 10^{5}$ cells in $50 \mu \mathrm{l}$ PBS $^{-}$with $1 \%(\mathrm{w} / \mathrm{v})$ BSA and $0.1 \%(\mathrm{w} / \mathrm{v})$ saponin. From then on, the same procedure was followed as for surface staining, except for the antibody-incubation which occurred at room temperature. The following monoclonal antibodies were used: anti-HLA-DR-phycoerythrin (PE) (clone L243), anti-CD83-PE (clone HB15e), anti-CD86-PE (clone IT2.2), anti-COX-2-PE (clone AS67) (BD Biosciences) and antiCCR2-PE (clone 48607.211) (R\&D Systems). Isotypic control antibodies IgG1-PE, IgG2b-PE and IgG2 $\alpha$-PE (BD Biosciences) were used to estimate the non-specific binding. After washing, cells were resuspended in $\mathrm{PBS}^{-}$with $1 \%(\mathrm{v} / \mathrm{v})$ formaldehyde. Flow cytometric analysis was performed on a FACSCalibur (BD Biosciences).

CD34-DC were identified by light scatter, gates were set to exclude dead cells and cell debris, which were determined using propidium iodide staining and fluorescence histograms were evaluated using CellQuest (BD Biosciences). To verify for any abnormality, isotypic controls were measured and evaluated to stain only $0.5 \%$ positive cells. Percentages of positive cells above this $0.5 \%$ and the geomean fluorescence intensity (MFI) were calculated. For assessment of phenotypical changes stimulation indices (SI) were calculated as follows: (\% positive cells $\times \mathrm{MFI}$ ) of chemical-treated cells, divided by (\% positive cells $\times$ MFI) of time-related control cells. The resulting SI data were transformed by a 2-base logarithm and further addressed as $\log _{2}$ SI. The mean $\log _{2}$ SI value of all 3 sensitizers and non-sensitizers was calculated ( \pm SEM) and tested for significant increases in response using a 2-sample equal variance 1tailed Student $t$-test. Values were considered significant when the $p$-value was less than 0.05 .

\section{Results}

\subsection{Network analysis}

To explore the mechanism by which the VITOSENS ${ }^{\circledR}$ classification model recognizes skin sensitizing chemicals, Ingenuity Pathways Analysis (IPA) was used to organize 13 genes with highly discriminating power into a network of interacting molecules. In Fig. 1 all molecules are presented as yellow nodes in their respective cellular compartment, and the lines in between them represent their interactions. Based on findings from the large Ingenuity peerreviewed literature database, the software added 44 molecules to 
Table 1

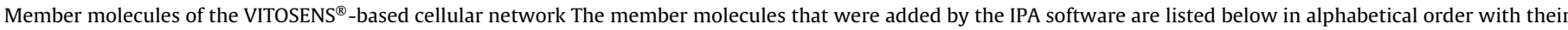

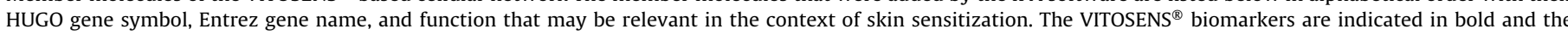
additionally analyzed network molecules in italic.

\begin{tabular}{|c|c|c|}
\hline Symbol & Entrez gene name & Functions \\
\hline ABCA6 & ATP-binding cassette, sub-family A ( $\mathrm{ABC} 1$ ), member 6 & ATP binding \\
\hline ADORA2A & Adenosine $\mathrm{A} 2 \mathrm{a}$ receptor & Cell-mediated immune response \\
\hline ADRBK2 & Adrenergic, beta, receptor kinase 2 & Signal transducer activity \\
\hline AQP3 & Aquaporin 3 (Gill blood group) & Water channel activity: positive regulation of immune system \\
\hline ATF1 & Activating transcription factor 1 & Transcription factor activity \\
\hline CAV1 & Caveolin 1, caveolae protein, $22 \mathrm{kDa}$ & Negative regulation of cytokine-mediated signaling pathway \\
\hline CCL2 & Chemokine ( $\mathrm{C}-\mathrm{C}$ motif) ligand 2 & Antigen presentation, cell-mediated immune response \\
\hline CCL5 & Chemokine ( $\mathrm{C}-\mathrm{C}$ motif) ligand 5 & Antigen presentation, cell-mediated immune response \\
\hline CCR2 & Chemokine ( $\mathrm{C}-\mathrm{C}$ motif) receptor 2 & Antigen presentation \\
\hline CCR5 & Chemokine ( $\mathrm{C}-\mathrm{C}$ motif) receptor 5 & Antigen presentation, cell-mediated immune response \\
\hline CCR7 & Chemokine ( $\mathrm{C}-\mathrm{C}$ motif) receptor 7 & Antigen presentation, cell-mediated immune response \\
\hline CEBPB & CCAAT/enhancer binding protein (C/EBP), beta & Cell-mediated immune response \\
\hline CREB1 & cAMP responsive element binding protein 1 & Cell-mediated immune response \\
\hline $\operatorname{cox} 2$ & $\begin{array}{l}\text { Cyclooxygenase (prostaglandin-endoperoxide synthase } 2 \text { and } \\
\text { prostaglandin G/H synthase) }\end{array}$ & $\begin{array}{l}\text { Dermatological disorder, antigen presentation, cell-mediated } \\
\text { immune response }\end{array}$ \\
\hline CREBBP & CREB binding protein & Cell-mediated immune response \\
\hline CREM & cAMP responsive element modulator & Transcription factor activity \\
\hline CSF2 & Colony stimulating factor 2 (granulocyte-macrophage) & $\begin{array}{l}\text { Dermatological disorder, antigen presentation, cell-mediated } \\
\text { immune response }\end{array}$ \\
\hline CXCL12 & $\begin{array}{l}\text { Chemokine (C-X-C motif) ligand } 12 \text { (stromal cell-derived } \\
\text { factor } 1 \text { ) }\end{array}$ & Antigen presentation, cell-mediated immune response \\
\hline CXCR4 & Chemokine (C-X-C motif) receptor 4 & $\begin{array}{l}\text { Dermatological disorder, antigen presentation, cell-mediated } \\
\text { immune response }\end{array}$ \\
\hline PSCDBP & Cytohesin 1 interacting protein & Regulation of cell adhesion \\
\hline EDN1 & Endothelin 1 & Antigen presentation \\
\hline EGR1 & Early growth response 1 & Cell-mediated immune response \\
\hline ENC1 & Ectodermal-neural cortex (with BTB-like domain) & Protein binding \\
\hline ЕР300 & E1A binding protein $\mathrm{p} 300$ & Cell-mediated immune response \\
\hline FOS & v-fos FBJ murine osteosarcoma viral oncogene homolog & Dermatological disorder, cell-mediated immune response \\
\hline GNAQ & Guanine nucleotide binding protein (G-protein), q polypeptide & G-protein coupled receptor protein signaling pathway \\
\hline HDAC1 & Histone deacetylase 1 & Transcription factor activity \\
\hline HDAC2 & Histone deacetylase 2 & Transcription factor activity \\
\hline IFNG & Interferon, gamma & $\begin{array}{l}\text { Dermatological disorder, antigen presentation, cell-mediated } \\
\text { immune response }\end{array}$ \\
\hline IGF1R & Insulin-like growth factor 1 receptor & Cell-mediated immune response \\
\hline IL-2 & Interleukin 2 & Antigen presentation, cell-mediated immune response \\
\hline IL-4 & Interleukin 4 & $\begin{array}{l}\text { Dermatological disorder, antigen presentation, cell-mediated } \\
\text { immune response }\end{array}$ \\
\hline IL-6 & Interleukin 6 (interferon, beta 2) & $\begin{array}{l}\text { Dermatological disorder, antigen presentation, cell-mediated } \\
\text { immune response }\end{array}$ \\
\hline IL-8 & Interleukin 8 & $\begin{array}{l}\text { Dermatological disorder, antigen presentation, cell-mediated } \\
\text { immune response }\end{array}$ \\
\hline IL-1 $\beta$ & Interleukin 1 , beta & $\begin{array}{l}\text { Dermatological disorder, antigen presentation, cell-mediated } \\
\text { immune response }\end{array}$ \\
\hline INSR & Insulin receptor & Dermatological disorder \\
\hline JAK2 & Janus kinase 2 & G-protein coupled receptor protein signaling pathway \\
\hline JUN & Jun oncogene & Dermatological disorder, cell-mediated immune response \\
\hline MAPK3 & Mitogen-activated protein kinase 3 & Cell-mediated immune response \\
\hline MXD1 & MAX dimerization protein 1 & Transcription factor activity \\
\hline PBEF1 & Pre-B-cell colony-enhancing factor 1 & Cytokine activity \\
\hline NFE2L2 & Nuclear factor (erythroid-derived 2)-like 2 & Cell-mediated immune response \\
\hline$N F \kappa \beta 1$ & $\begin{array}{l}\text { Nuclear factor of kappa light polypeptide gene enhancer in B } \\
\text { cells } 1\end{array}$ & Dermatological disorder, cell-mediated immune response \\
\hline NINJ1 & Ninjurin 1 & Cell adhesion \\
\hline NOS2 & Nitric oxide synthase 2 , inducible & Antigen presentation \\
\hline PLD2 & Phospholipase D2 & Receptor-mediated endocytosis \\
\hline POMC & Proopiomelanocortin & $\begin{array}{l}\text { Dermatological disorder, antigen presentation, cell-mediated } \\
\text { immune response }\end{array}$ \\
\hline PTGER2 & Prostaglandin E receptor 2 (subtype EP2), $53 \mathrm{kDa}$ & G-protein coupled receptor protein signaling pathway \\
\hline PTGER4 & Prostaglandin E receptor 4 (subtype EP4) & G-protein coupled receptor protein signaling pathway \\
\hline RARB & Retinoic acid receptor, beta & Dermatological disorder \\
\hline RELA & v-rel reticuloendotheliosis viral oncogene homolog A (avian) & Dermatological disorder, cell-mediated immune response \\
\hline $\mathrm{SLC} 2 \mathrm{~A} 3$ & $\begin{array}{l}\text { Solute carrier family } 2 \text { (facilitated glucose transporter), } \\
\text { member } 3\end{array}$ & Substrate-specific transmembrane transporter activity \\
\hline STAT3 & $\begin{array}{l}\text { Signal transducer and activator of transcription } 3 \text { (acute-phase } \\
\text { response factor) }\end{array}$ & $\begin{array}{l}\text { Dermatological disorder, antigen presentation, cell-mediated } \\
\text { immune response }\end{array}$ \\
\hline TBP & TATA box binding protein & Transcription factor activity \\
\hline TNF & Tumor necrosis factor (TNF superfamily, member 2) & $\begin{array}{l}\text { Dermatological disorder, antigen presentation, cell-mediated } \\
\text { immune response }\end{array}$ \\
\hline TP53 & Tumor protein p53 & Dermatological disorder, cell-mediated immune response \\
\hline VEGFA & Vascular endothelial growth factor A & $\begin{array}{l}\text { Dermatological disorder, antigen presentation, cell-mediated } \\
\text { immune response }\end{array}$ \\
\hline
\end{tabular}


Table 2

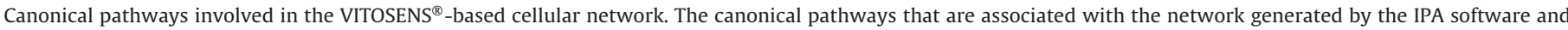
contained at least 10 network molecules. The pathways are ranked below according to the number and mentioning the names of involved molecules.

\begin{tabular}{|c|c|c|}
\hline Canonical pathway name & \# & Molecules \\
\hline Glucocorticoid receptor signaling & 24 & $\begin{array}{l}\text { CCL2, CCL5, CEBPB, CREB1, CREBBP, CSF2, EP300, FOS, IFN } \gamma \text {, } \\
\text { IL-2, IL-4, IL-6, IL-8, IL-1 } \beta \text {, JAK2, JUN, MAPK3, NF-к } \beta 1 \text {, } \\
\text { NOS2, POMC, RELA (includes EG:5970), STAT3, TBP, TNF }\end{array}$ \\
\hline IL-6 signaling & 12 & $\begin{array}{l}\text { CEBPB, FOS, IL-6, IL-8, IL-1 } \beta \text {, JAK2, JUN, MAPK3, NF-к } \beta 1 \text {, } \\
\text { RELA (includes EG:5970), STAT3, TNF }\end{array}$ \\
\hline Aryl hydrocarbon receptor signaling & 12 & $\begin{array}{l}\text { EP300, FOS, IL-6, IL-1 } \beta, \text { JUN, MAPK3, NFE2L2, NF-к } \beta 1 \text {, } \\
\text { RARB, RELA (includes EG:5970), TNF, TP53 }\end{array}$ \\
\hline Renin-angiotensin signaling & 12 & $\begin{array}{l}\text { CCL2, CCL5, FOS, GNAQ JAK2, JUN, MAPK3, NF-к } \beta 1 \text {, } \\
\text { PTGER2, RELA (includes EG:5970), STAT3, TNF }\end{array}$ \\
\hline Trem1 signaling & 11 & $\begin{array}{l}\text { CCL2, CSF2, IL-6, IL-8, IL-1 } \beta \text {, JAK2, MAPK3, NF-к } \beta 1 \text {, RELA } \\
\text { (includes EG:5970), STAT3, TNF }\end{array}$ \\
\hline IL-12 signaling and production in macrophages & 11 & $\begin{array}{l}\text { CEBPB, EP300, FOS, IFNG, IL-4, JUN, MAPK3, NF-к } \beta 1 \text {, NOS2, } \\
\text { RELA (includes EG:5970), TNF }\end{array}$ \\
\hline $\operatorname{PPAR} \alpha / \mathrm{RXR} \alpha$ activation & 11 & $\begin{array}{l}\text { CREBBP, EP300, GNAQ, IL-6, IL-1 } \beta \text {, INSR, JAK2, JUN, MAPK3, } \\
\text { NF- } \kappa \beta 1 \text {, RELA (includes EG:5970) }\end{array}$ \\
\hline IL-17 signaling & 11 & $\begin{array}{l}\text { CCL2, CEBPB, COX2, IL-6, IL-8, JAK2, JUN, MAPK3, NF-к } \beta 1 \text {, } \\
\text { NOS2, RELA (includes EG:5970) }\end{array}$ \\
\hline Production of nitric oxide and reactive oxygen species in macrophages & 11 & $\begin{array}{l}\text { CREBBP, FOS, IFNG, IL-4, JAK2, JUN, MAPK3, NF-к } \beta 1 \text {, NOS2, } \\
\text { RELA (includes EG:5970), TNF }\end{array}$ \\
\hline Acute-phase response signaling & 11 & $\begin{array}{l}\text { CEBPB, FOS, IL-6, IL-1ß, JAK2, JUN, MAPK3, NF-к } \beta 1 \text {, RELA } \\
\text { (includes EG:5970), STAT3, TNF }\end{array}$ \\
\hline Dendritic cell maturation & 10 & $\begin{array}{l}\text { CCR7, CREB1, CSF2, IL-6, IL-1 } \beta, \text { JAK2, MAPK3, NF-к } \beta 1 \text {, } \\
\text { RELA (includes EG:5970), TNF }\end{array}$ \\
\hline Xenobiotic metabolism signaling & 10 & $\begin{array}{l}\text { CREBBP, EP300, IL-6, IL-1B, MAPK3, NFE2L2, NF-к } \beta 1 \text {, } \\
\text { NOS2, RELA (includes EG:5970), TNF }\end{array}$ \\
\hline Communication between innate and adaptive immune cells & 10 & CCL5, CCR7, CSF2, IFN $\gamma$, IL-2, IL-4, IL-6, IL-8, IL-1 $\beta$, TNF \\
\hline PPAR signaling & 10 & $\begin{array}{l}\text { CREBBP, EP300, FOS, IL-1 } \beta \text {, INSR, JUN, MAPK3, NF-к } \beta 1 \text {, } \\
\text { RELA (includes EG:5970), TNF }\end{array}$ \\
\hline ILK signaling & 10 & $\begin{array}{l}\text { COX2, CREB1, FOS, JUN, MAPK3, NF-к } \beta 1 \text {, NOS2, RELA } \\
\text { (includes EG:5970), TNF, VEGFA }\end{array}$ \\
\hline
\end{tabular}

the original set of 13 marker genes in the network. Overall, the created interactome contained 20 nuclear molecules, 7 network members in the cellular cytoplasm, 15 molecules were located in the cell's plasma membrane, and the remaining 15 nodes were situated in the extra-cellular space.

In the network presented, COX2 is in a central position being influenced by a large number of network members and persevering itself. COX2 interferes with the VITOSENS ${ }^{\circledR}$ biomarkers CCR7 and chemokine ( $\mathrm{C}-\mathrm{X}-\mathrm{C}$ motif) receptor (CXCR) 4, and is directly regulated via a feedback loop and transcription factors, such as nuclear factor (erythroid-derived 2)-like 2 (Nfe2l2 or Nrf2), and indirectly via CREM and MAX dimerization protein (MXD)1. Also CREM, CXCR4 and CCR2 appear to be highly interconnected with other nodes in the network. CXCR4 interconnects with CCR2 and COX2, and CCR2 also regulates its own expression.

For each member of the network, a description of the name and function is listed in Table 1. Twenty-six of 57 network molecules were functionally involved in antigen presentation, 33 in cellmediated immune responses and 20 in dermatological disorders. Overlaying the network with canonical pathways showed that the network molecules took part in 180 different canonical pathways. The pathways containing 10 or more member molecules are represented in Table 2 and included relevant cascades for skin sensitization, like glucocorticoid (GC) receptor signaling (24 molecules), IL-12 signaling (11), and DC maturation (10). Some of the molecules are present in multiple pathways of which not necessarily all are related to skin sensitization. As such, these pathways were removed from Table 2: colorectal cancer metastasis signaling (17), hepatic fibrosis (15), molecular mechanisms of cancer (10), and Huntington's disease signaling (10).

Biological relevance of the network in exposed CD34-DC was verified by measuring the expression of 3 member genes other than the 13 genetic markers, using real-time RT-qPCR on the same CD34-DC samples that were used to develop the VITOSENS ${ }^{\circledR}$ classi- fication model. cAMP responsive element binding protein (CREB)1, nuclear factor of kappa light polypeptide gene enhancer in $B$ cells (p105) $(N F-\kappa B) 1$, and tumour necrosis factor $\alpha(T N F-\alpha)$ were selected because of the number of connections with the VITOSENS ${ }^{\circledR}$ biomarkers (indicated in black in Fig. 1) and because their biological role was highly relevant for the skin sensitization process (see Section 4).

The samples used in this study had been exposed to 9 skin sensitizing compounds (2-MBT, CA, DNCB, DNBS, DNFB, eugenol, $\mathrm{HCPt}, \mathrm{NiSO}_{4}$, and TMTD) and 5 non-sensitizers (MeSA, pABA, phenol, SDS, and $\mathrm{ZnSO}_{4}$ ) (Hooyberghs et al., 2008). Expression of all 3 genes could be detected in both skin sensitizer and non-sensitizer exposed CD34-DC and the induced mean LFC are visualized in a heatmap (Fig. 2). From this, it can be observed that CREB1 showed strongest stimulation after 11 and $24 \mathrm{~h}$ of skin sensitizing exposure but at the latter time point, also nonsensitizers induced expression of this gene. Overall expression of $N F-\kappa B 1$ is inhibited by skin sensitizers, except for $\mathrm{NiSO}_{4}$ and 2 -MBT which seem to induce expression of this gene at $11 \mathrm{~h}$, and 11 and $24 \mathrm{~h}$ of exposure, respectively. Of the non-sensitizers, SDS and pABA slightly stimulate $N F-\kappa B 1$ expression. TNF- $\alpha$ on the other hand, is up-regulated by all skin sensitizers and for most of them after 11 and $24 \mathrm{~h}$ of exposure, except for $\mathrm{NiSO}_{4}$ who again starts to inhibit expression of this molecule after $24 \mathrm{~h}$ treatment. The non-sensitizing substances seem to induce a similar expression profile for this molecule, but the stimulation is limited.

When comparing the LFC of these 3 genes in CD34-DC after sensitizing versus non-sensitizing treatment (Fig. 3), the stimulation of CREB1 was significantly lower after $24 \mathrm{~h}$ of skin sensitizing versus non-sensitizing exposure ( $p=0.045)$. On the contrary, expression of $T N F-\alpha$ was significantly induced by sensitizers compared to nonsensitizers after $11 \mathrm{~h}$ treatment $(p=0.003)$. NF- $\kappa B 1$ did not show a significantly different expression profile between the 2 sets of chemicals. 


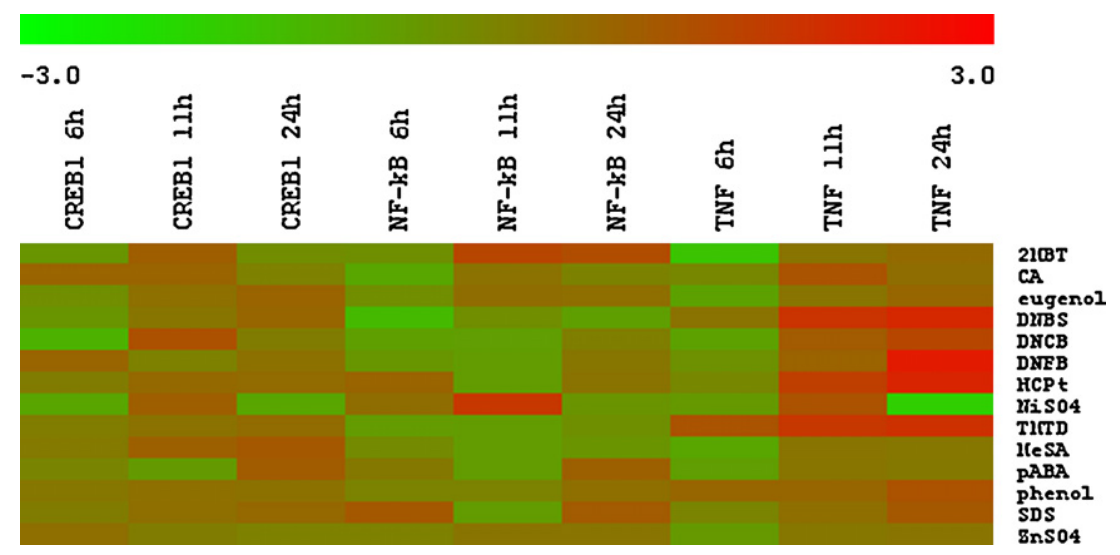

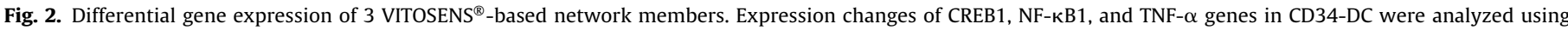

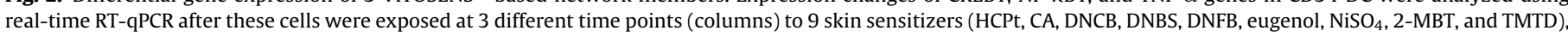

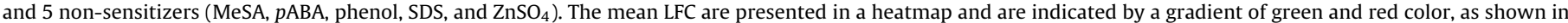
the color scale at the top of the heatmap. The red color indicates up-regulated and the green color down-regulated gene expression.

\subsection{Protein detection}

To evaluate whether the VITOSENS ${ }^{\circledR}$ genes were actually translated into proteins we analyzed the expression of the intracellular proteins CCR2 and COX2 which may play a central role as suggested by the network analysis. Preliminary experiments on time kinetics going from 6 to $96 \mathrm{~h}$ of exposure were first performed and 24 and $48 \mathrm{~h}$ of exposure appeared to contain the most relevant information (data not shown). After 24 and $48 \mathrm{~h}$ of exposure of CD34-DC to 3 sensitizers (DHQ DNFB and $2-\mathrm{MBT}$ ) versus 3 non-sensitizers (DMSO, MeSA, and $\mathrm{ZnSO}_{4}$ ), differential expression of CCR2 and COX2 was evaluated by means of flow cytometry. As a control for DC activation, the surface markers HLA-DR, CD86, and CD83 were also evaluated. Exposing CD34-DC for $24 \mathrm{~h}$ to sensitizing chemicals induced a significant rise in expression of HLA-DR $(p=0.0002), \operatorname{COX} 2(p=0.04)$, and CCR2 $(p=0.02)$ compared to non-sensitizing exposure (Fig. 4a). After $48 \mathrm{~h}$ of sensitizing treatment, again HLA-DR $(p=0.004)$, COX2 $(p=0.006)$, and also CD86 $(p=0.02)$ showed significantly higher expression levels compared to non-sensitizing exposure (Fig. 4b). Overall, the protein expression of the DC activation markers and COX2 was induced by chemical sensitizers relative to solvent, while CCR2 expression was inhibited. Non-sensitizing chemicals did not exert noticeable changes on marker expression $\left(\log _{2} \mathrm{SI}<|0.5|\right)$.

\section{Discussion}

The objective of this study was to acquire knowledge on the mechanism by which the VITOSENS ${ }^{\circledR}$ assay is able to discriminate skin sensitizing from non-sensitizing chemicals. VITOSENS ${ }^{\circledR}$ is based on the expression of CREM and CCR2, and along with these molecules, 11 others were observed to behave highly discriminating in the molecular cascade in CD34-DC upon sensitizing versus non-sensitizing exposure.

Using the IPA software, possible relationships between the 13 VITOSENS $^{\circledR}$ biomarkers were investigated. Screening the literature findings, the software integrated the molecules in a virtual network containing 57 molecules, out of which 26 were involved in antigen presentation. Further, it appeared that the network contained 24 molecules that are involved in GC receptor signaling, 11 members take part in IL-12 signaling and that the DC maturation pathway overlaps with 10 network molecules. Besides DC maturation, IL12 signaling is known to occur in antigen-presenting DC (Martin et al., 2008; Saint-Mezard et al., 2004) and GC promote migration of cutaneous DC into the lymph nodes and T cell-mediated immunity (Kamimura et al., 2009). This indicates that the network constructed on the basis of the VITOSENS ${ }^{\circledR}$ biomarkers contains members that may be relevant for DC mediated skin sensitization.

A central effector role in the network was revealed for COX2. $\mathrm{COX} 2$ is the key enzyme in prostaglandin biosynthesis and is known

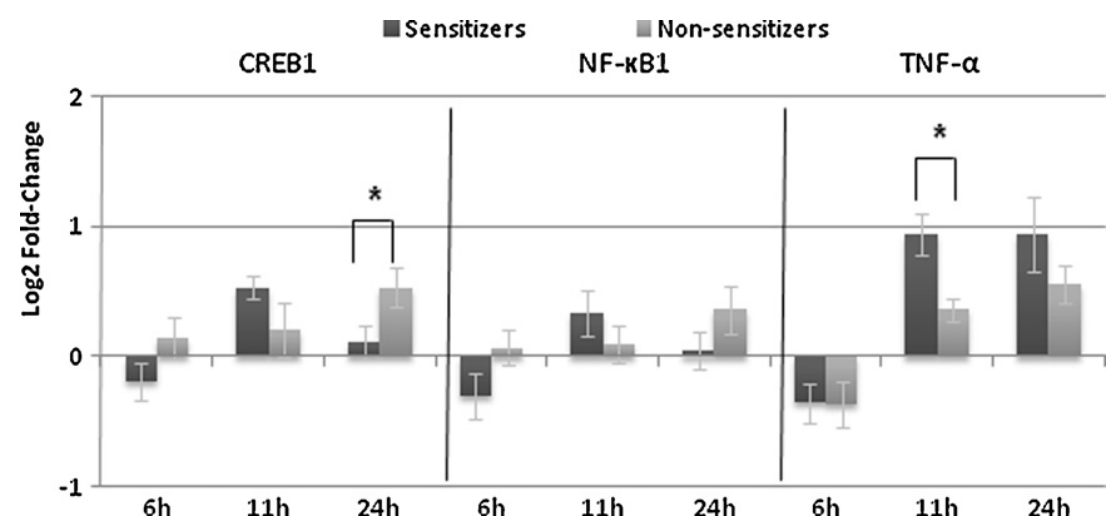

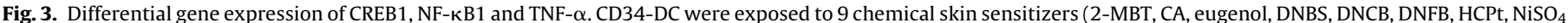

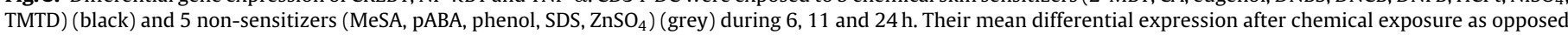

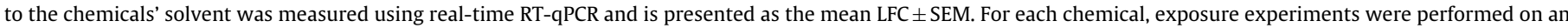
average of 3 biological donor samples. Significant differences in expression between sensitizing and non-sensitizing exposure are indicated with an * $p<0.05$. 

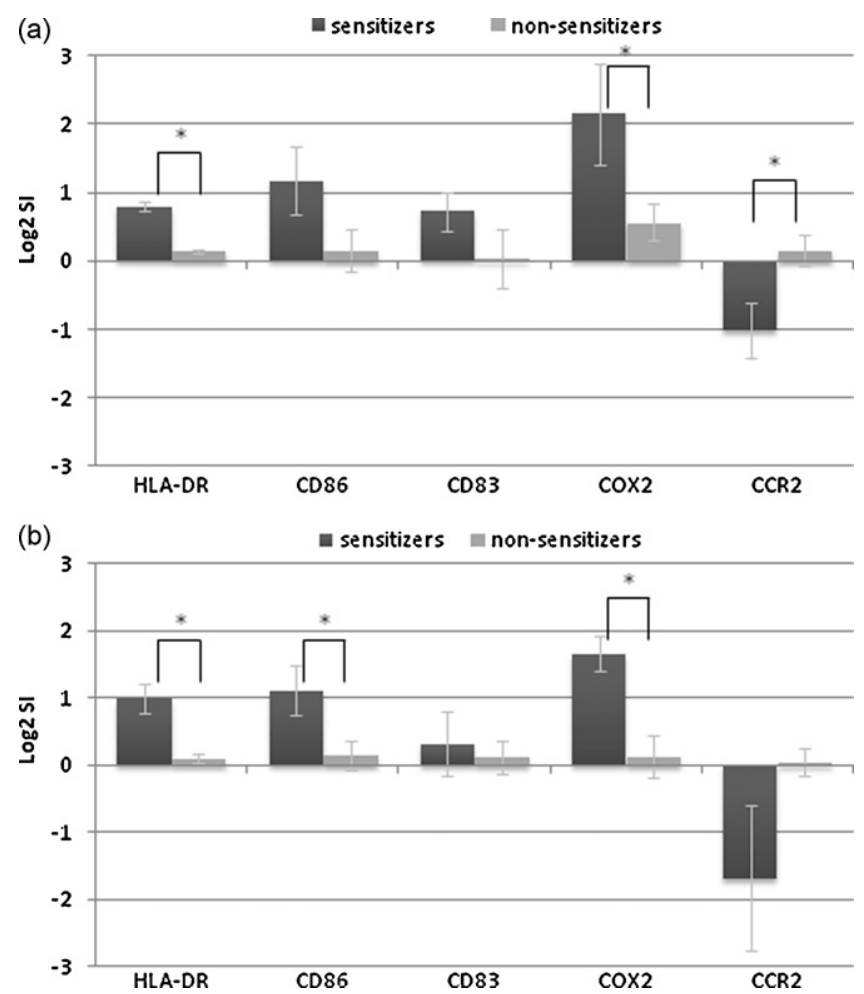

Fig. 4. Differential protein expression of DC maturation markers, COX2 and CCR2. CD34-DC were exposed for $24 \mathrm{~h}(\mathrm{a})$ and $48 \mathrm{~h}$ (b) to 3 sensitizers (DNFB, DHQ and 2$\mathrm{MBT}$ ) and 3 non-sensitizers (DMSO, MeSA, and $\mathrm{ZnSO}_{4}$ ). Each chemical was applied on 3 independent donor samples. After flow cytometry analysis, the differential protein expression was considered as the mean $\log _{2}$ stimulation index (SI) \pm SEM after exposure to (non-)sensitizers relative to their solvent. Significant differences between sensitizing and non-sensitizing exposures $(p<0.05)$ are indicated with *

to be associated with biologic events such as injury, inflammation, and proliferation (Hla and Neilson, 1992; Tazawa et al., 1994). In the network, Nrf2 directly influences COX2 which might explain the stimulation of this enzyme in our CD34-DC model after exposure to sensitizers. Indeed, the Nrf2 pathway has been described frequently to be induced by chemical sensitizers (Ade et al., 2009; Natsch and Emter, 2008). Further, CREM and CCR2, the VITOSENS ${ }^{\circledR}$ genes with highest discriminating power (Hooyberghs et al., 2008), were also highly interconnected with other molecules in the generated network. The observation that the transcription modulator CREM was a central node in the network could be explained by its role as point of potential convergence for multiple intracellular signaling cascades (Mayr and Montminy, 2001). The high number of interactions that were established by COX2 and CREM indicated that these molecules might be highly relevant in coordinating molecular events in sensitizer exposed CD34-DC.

To verify whether 'key signaling molecules' as indicated by the in silico network analysis were actually expressed in our DC model, real-time RT-qPCR experiments were performed on CREB1, NF- $\kappa B 1$ and $T N F-\alpha$. These molecules were selected due to their connections with the VITOSENS ${ }^{\circledR}$ biomarkers and their biological relevance for sensitization related processes.

CREB1 directly affects solute carrier family 2 (facilitated glucose transporter) member 3 (SLC2A3) and COX2, and is influenced by CREM, the most discriminating gene in (non-)sensitizing exposed CD34-DC (Hooyberghs et al., 2008). Like CREM, CREB1 is a member of the cAMP responsive element (CRE) nuclear factor family (Solomou et al., 2001) and it has been established before that CRE-dependent transcription positively regulates cell adhesion, including the molecule CD54, during human myeloid differentiation (Saeki et al., 2003). Furthermore, CREB1 is involved in the transcription of immune regulatory genes, such as TNF- $\alpha, I L-2$, COX2, and IL-6 (Mayr and Montminy, 2001). This may explain the detectable and up-regulated levels of CREB1 expression in CD34DC after 11 and $24 \mathrm{~h}$ of skin sensitizing exposure relative to solvent exposure. Skin sensitizers induced a more rapid expression of CREB1 (after $11 \mathrm{~h}$ ), as opposed to the non-sensitizers which cause a significantly stronger stimulation only after $24 \mathrm{~h}$ of exposure.

$N F-\kappa B 1$ is a member of the NF- $\kappa B$ group which has been reported previously to be involved in the intracellular cascade induced by skin sensitizers (Ade et al., 2007). This molecule regulates COX2 and is influenced by CXCR4. In our results, we could not observe a significant difference of $N F-\kappa B 1$ expression after sensitizing versus non-sensitizing exposure. This was due in part to the large inter-compound variation that was observed for this gene after sensitizing exposure. It has been reported frequently that different chemicals may trigger different activation routes in antigen-presenting cells (Ade et al., 2007; Boisleve et al., 2005; Koeper et al., 2007; Miyazawa et al., 2008; Takanami-Ohnishi et al., 2002) and this may explain why for instance $\mathrm{NiSO}_{4}$ and 2-MBT strongly induce $N F-\kappa B 1$ at few time points as opposed to the other sensitizing chemicals.

TNF- $\alpha$ is the 3rd network member that was selected to be analyzed since it is a key regulator of the inflammatory response and since it is connected to 8 nodes in the network. It was previously shown that TNF- $\alpha$ is constitutively expressed by CD34-DC and that production could be enhanced by treatment of the cells with chemical sensitizers such as nickel chloride (De Smedt et al., 2001). This was confirmed by our results where TNF- $\alpha$ is significantly up-regulated after $11 \mathrm{~h}$ of skin sensitizing exposure versus non-sensitizing chemicals.

The identification of these additional molecular markers may be relevant for further exploration of the biological pathways that are associated with chemical-induced skin sensitization.

Based on their high discriminating power and central roles in the network, the VITOSENS ${ }^{\circledR}$ biomarker genes CCR2 and COX2 were selected for further functional analysis. By performing flow cytometry experiments on skin sensitizer and non-sensitizer exposed CD34-DC, we wanted to investigate whether the biomarker genes of CCR2 and COX2 were translated into proteins that showed a similar differential expression pattern. Also, DC surface markers HLA-DR, CD83 and CD86 were evaluated for checking a sensitizer induced maturation status. Expression of CD86 and HLA-DR was significantly increased after sensitizing exposure as opposed to treatment with non-sensitizers. This was expected since HLA-DR and CD86 are well-known DC maturation markers and in earlier studies we observed their up-regulation after exposure of CD34-DC to multiple sensitizers (De Smedt et al., 2001, 2005). While as expected the differential expression of these maturation markers proved positive in our cell model, the expression of the novel skin sensitization markers CCR2 and COX2 appeared to be even more pronounced at the protein level. CCR2 encodes a transmembrane monocyte chemoattractant protein receptor (Wong et al., 1997). Protein expression of CCR2 was significantly reduced after $24 \mathrm{~h}$ of sensitizing treatment of CD34-DC, whereas the expression after non-sensitizing exposure was not altered. The differential expression of the CCR2 protein indicates that it may exert a functional role in DC activation by chemical skin sensitization. A possible role may be the fact that after exposure to inflammatory stimuli, immature DC respond to macrophage-derived chemokines through CCR2, but upon maturation DC loose the responsiveness to these chemokines by receptor downregulation or desensitization (Merad et al., 2002).

Translation of the COX2 protein was significantly elevated by sensitizing chemicals compared to non-sensitizers at both time points. Harizi et al. (2001) already indicated that this regulator of prostaglandin E2 (PGE2) synthesis might play a role in antigen presentation in DC exposed to lipopolysaccharide. PGE2 is referred to 
as a potent Th2-promoting factor (Goodwin, 1989), while chemicalinduced skin sensitization is claimed to be Th1-mediated (Kimber and Dearman, 2002). Such contradictory results may be due to PGE2's quite complex actions on immune inflammatory response (Harizi and Gualde, 2005), as well as to the different nature of the stimulus and of the species from which DC were derived.

In future experiments the functional role of these markers and of other interesting molecules such as CREM, will be further investigated.

Altogether, several conclusions can be drawn from our study. First, relationships between 13 VITOSENS ${ }^{\circledR}$ biomarkers were identified in a network that might effectively be activated after skin sensitizing chemical exposure of CD34-DC as was shown by the differential expression of CREB1 and TNF- $\alpha$. Based on these results, CREM and COX2 appeared to be potential regulators in skin sensitization pathways in DC. Next, we established the significantly differential protein expression of this COX2 molecule, as well as of the highly discriminating CCR2 marker in sensitizer versus nonsensitizer induced CD34-DC. Besides these 2 markers, investigation of other molecules such as CREM might further add in the mechanistic insights of the VITOSENS assay ${ }^{\circledR}$.

This research illustrates that novel biomarker genes that were identified in sensitizer exposed CD34-DC using genomics are actually translated into proteins, and therefore they may take part in the biological process by which DC activate and present chemical haptens to naïve $\mathrm{T}$ cells.

\section{Conflict of interest}

The authors state no conflict of interest.

\section{Acknowledgements}

This project was co-funded by the John Hopkins Institute for Alternatives to Animal Testing (CAAT) [Project \#2009-11]. Nathalie Lambrechts was supported by a VITO PhD fellowship. For expert advice and technical assistance the authors are grateful to Karen Hollanders, Hilde Leppens, Daniëlla Ooms and Julie Van Gorp. The authors thank the delivery nursing staff and gynecologists of the Heilig Hart Hospital in Mol, Belgium and the St. Dimpna Hospital in Geel, Belgium for their help in collecting the cord blood samples.

\section{References}

Ade, N., Antonios, D., Kerdine-Romer, S., Boisleve, F., Rousset, F., Pallardy, M., 2007. NF-kappaB plays a major role in the maturation of human dendritic cells induced by NiSO(4) but not by DNCB. Toxicol. Sci. 99, 488-501.

Ade, N., Leon, F., Pallardy, M., Peiffer, J.L., Kerdine-Romer, S., Tissier, M.H., et al., 2009. HMOX1 and NQO1 genes are upregulated in response to contact sensitizers in dendritic cells and THP-1 cell line: role of the Keap1/Nrf2 pathway. Toxicol. Sci. 107, 451-460.

Banchereau, J., Steinman, R.M., 1998. Dendritic cells and the control of immunity. Nature 392, 245-252.

Boisleve, F., Kerdine-Romer, S., Pallardy, M., 2005. Implication of the MAPK pathways in the maturation of human dendritic cells induced by nickel and TNF-[alpha]. Toxicology 206, 233.

Casati, S., Aeby, P., Basketter, D.A., Cavani, A., Gennari, A., Gerberick, G.F., et al., 2005. Dendritic cells as a tool for the predictive identification of skin sensitisation hazard. Altern. Lab. Anim. 33, 47-62.

Caux, C., Vanbervliet, B., Massacrier, C., Dezutter-Dambuyant, C., de Saint-Vis, B., Jacquet, C., et al., 1996. CD $34^{+}$hematopoietic progenitors from human cord blood differentiate along two independent dendritic cell pathways in response to GMCSF+ TNF alpha. J. Exp. Med. 184, 695-706.

Cella, M., Engering, A., Pinet, V., Pieters, J., Lanzavecchia, A., 1997. Inflammatory stimuli induce accumulation of MHC class II complexes on dendritic cells. Nature 388, 782-787.

Charo, I.F., Myers, S.J., Herman, A., Franci, C., Connolly, A.J., Coughlin, S.R., 1994. Molecular cloning and functional expression of two monocyte chemoattractant protein 1 receptors reveals alternative splicing of the carboxyl-terminal tails. Proc. Natl. Acad. Sci. U.S.A. 91, 2752-2756.

Cluzel-Tailhardat, M., Bonnet-Duquennoy, M., de Queral, D.P., Vocanson, M., Kurfurst, R., Courtellemont, P., et al., 2007. Chemicals with weak skin sensitizing properties can be identified using low-density microarrays on immature dendritic cells. Toxicol. Lett. 174, 98-109.

De Smedt, A.C., Van Den Heuvel, R.L., Van Tendeloo, V.F., Berneman, Z.N., Schoeters, G.E., 2005. Capacity of CD $34^{+}$progenitor-derived dendritic cells to distinguish between sensitizers and irritants. Toxicol. Lett. 156, 377-389.

De Smedt, A.C.A., Van Den Heuvel, R.L., Zwi Berneman, N., Schoeters, G.E.R., 2001 Modulation of phenotype, cytokine production and stimulatory function of CD34 ${ }^{+}$-derived DC by $\mathrm{NiCl}_{2}$ and SDS. Toxicol. In Vitro 15, 319.

dos Santos, G.G., Reinders, J., Ouwehand, K., Rustemeyer, T., Scheper, R.J., Gibbs S., 2009. Progress on the development of human in vitro dendritic cell based assays for assessment of the sensitizing potential of a compound. Toxicol. Appl. Pharmacol. 236, 372-382.

Goodwin, J.S., 1989. Immunomodulation by eicosanoids and anti-inflammatory drugs. Curr. Opin. Immunol. 2, 264-268.

Harizi, H., Gualde, N., 2005. The impact of eicosanoids on the crosstalk between innate and adaptive immunity: the key roles of dendritic cells. Tissue Antigens $65,507-514$.

Harizi, H., Juzan, M., Grosset, C., Rashedi, M., Gualde, N., 2001. Dendritic cells issued in vitro from bone marrow produce PGE(2) that contributes to the immunomodulation induced by antigen-presenting cells. Cell. Immunol. 209, 19-28.

Hellemans, J., Mortier, G., De Paepe, A., Speleman, F., Vandesompele, J., 2007. qBase relative quantification framework and software for management and automated analysis of real-time quantitative PCR data. Genome Biol. 8, R19.

Hla, T., Neilson, K., 1992. Human cyclooxygenase-2 cDNA. Proc. Natl. Acad. Sci. U.S.A 89, 7384-7388.

Hooyberghs, J., Schoeters, E., Lambrechts, N., Nelissen, I., Witters, H., Schoeters, G., et al., 2008. A cell-based in vitro alternative to identify skin sensitizers by gene expression. Toxicol. Appl. Pharmacol. 231, 103-111.

Inaba, K., Inaba, M., Romani, N., Aya, H., Deguchi, M., Ikehara, S., et al., 1992. Generation of large numbers of dendritic cells from mouse bone marrow cultures supplemented with granulocyte/macrophage colony-stimulating factor. J. Exp. Med. 176, 1693-1702.

Kamimura, Y., Iwai, H., Piao, J., Hashiguchi, M., Azuma, M., 2009. The glucocorticoidinduced TNF receptor-related protein (GITR)-GITR ligand pathway acts as a mediator of cutaneous dendritic cell migration and promotes T cell-mediated acquired immunity. J. Immunol. 182, 2708-2716.

Kimber, I., Dearman, R.J., 2002. Allergic contact dermatitis: the cellular effectors Contact Dermat. 46, 1-5.

Koeper, L.M., Schulz, A., Ahr, H.J., Vohr, H.W., 2007. In vitro differentiation of skin sensitizers by cell signaling pathways. Toxicology 242, 144-152.

Lambrechts, N., Vanheel, H., Nelissen, I., Witters, H., Van Den Heuvel, R., Van Tendeloo, V., et al., 2010. Potency assessment of chemical skin sensitizers by an in vitro assay based on human dendritic cells. Toxicol. Sci, doi:10.1093/toxsci/kfq108.

Lardon, F., Snoeck, H.W., Berneman, Z.N., Van Tendeloo, V.F., Nijs, G., Lenjou, M., et al., 1997. Generation of dendritic cells from bone marrow progenitors using GM-CSF, TNF-alpha, and additional cytokines: antagonistic effects of IL-4 and IFN-gamma and selective involvement of TNF-alpha receptor-1. Immunology 91, 553-559.

Lenz, A., Heine, M., Schuler, G., Romani, N., 1993. Human and murine dermis contain dendritic cells. Isolation by means of a novel method and phenotypical and functional characterization. J. Clin. Invest. 92, 2587-2596.

Martin, S.F., Dudda, J.C., Bachtanian, E., Lembo, A., Liller, S., Durr, C., et al., 2008 Toll-like receptor and IL-12 signaling control susceptibility to contact hypersensitivity. J. Exp. Med. 205, 2151-2162.

Mayr, B., Montminy, M., 2001. Transcriptional regulation by the phosphorylationdependent factor CREB. Nat. Rev. Mol. Cell. Biol. 2, 599-609.

Merad, M., Manz, M.G., Karsunky, H., Wagers, A., Peters, W., Charo, I., et al., 2002. Langerhans cells renew in the skin throughout life under steady-state conditions. Nat. Immunol. 3, 1135-1141.

Miyazawa, M., Ito, Y., Kosaka, N., Nukada, Y., Sakaguchi, H., Suzuki, H., et al., 2008. Role of MAPK signaling pathway in the activation of dendritic type cell line THP-1, induced by DNCB and $\mathrm{NiSO}_{4}$. J. Toxicol. Sci. 33, 51-59.

Natsch, A., Emter, R., 2008. Skin sensitizers induce antioxidant response element dependent genes: application to the in vitro testing of the sensitization potential of chemicals. Toxicol. Sci. 102, 110-119.

Romani, N., Gruner, S., Brang, D., Kampgen, E., Lenz, A., Trockenbacher, B., et al., 1994 Proliferating dendritic cell progenitors in human blood. J. Exp. Med. 180, 83-93.

Ryan, C.A., Gildea, L.A., Hulette, B.C., Dearman, R.J., Kimber, I., Gerberick, G.F., 2004. Gene expression changes in peripheral blood-derived dendritic cells following exposure to a contact allergen. Toxicol. Lett. 150, 301-316.

Ryan, C.A., Kimber, I., Basketter, D.A., Pallardy, M., Gildea, L.A., Gerberick, G.F., 2007 Dendritic cells and skin sensitization: biological roles and uses in hazard identification. Toxicol. Appl. Pharmacol. 221, 384-394.

Saeki, K., Saeki, K., Yuo, A., 2003. Distinct involvement of cAMP-response elementdependent transcriptions in functional and morphological maturation during retinoid-mediated human myeloid differentiation. J. Leukoc. Biol. 73, 673-681.

Saint-Mezard, P., Rosieres, A., Krasteva, M., Berard, F., Dubois, B., Kaiserlian, D., et al., 2004. Allergic contact dermatitis. Eur. J. Dermatol. 14, 284-295.

Sallusto, F., Lanzavecchia, A., 1994. Efficient presentation of soluble antigen by cultured human dendritic cells is maintained by granulocyte/macrophage colony-stimulating factor plus interleukin 4 and downregulated by tumor necrosis factor alpha. J. Exp. Med. 179, 1109-1118.

Schoeters, E., Verheyen, G.R., Nelissen, I., Van Rompay, A.R., Hooyberghs, J., Van Den Heuvel, R.L., et al., 2007. Microarray analyses in dendritic cells revea potential biomarkers for chemical-induced skin sensitization. Mol. Immunol. $44,3222-3233$. 
Solomou, E.E., Juang, Y.T., Gourley, M.F., Kammer, G.M., Tsokos, G.C., 2001. Molecular basis of deficient IL-2 production in T cells from patients with systemic lupus erythematosus. J. Immunol. 166, 4216-4222.

Szameit, S., Vierlinger, K., Farmer, L., Tuschl, H., Noehammer, C., 2008. Microarraybased in vitro test system for the discrimination of contact allergens and irritants: identification of potential marker genes. Clin. Chem. 54, 525-533.

Szameit, S., Vierlinger, K., Farmer, L., Tuschl, H., Noehammer, C., 2009. Gene expression studies in cultured dendritic cells: new indicators for the discrimination of skin sensitizers and irritants in vitro. Clin. Exp. Allergy 39, 856-868.
Takanami-Ohnishi, Y., Amano, S., Kimura, S., Asada, S., Utani, A., Maruyama, M., et al., 2002. Essential role of p38 mitogen-activated protein kinase in contact hypersensitivity. J. Biol. Chem. 277, 37896-37903.

Tazawa, R., Xu, X.M., Wu, K.K., Wang, L.H., 1994. Characterization of the genomic structure, chromosomal location and promoter of human prostaglandin $\mathrm{H}$ synthase-2 gene. Biochem. Biophys. Res. Commun. 203, 190-199.

Wong, L.M., Myers, S.J., Tsou, C.L., Gosling, J., Arai, H., Charo, I.F., 1997. Organization and differential expression of the human monocyte chemoattractant protein 1 receptor gene. Evidence for the role of the carboxyl-terminal tail in receptor trafficking. J. Biol. Chem. 272, 1038-1045. 